\title{
Comunicación para el cambio social: interconectando experiencias y aprendizajes de dentro y fuera de la academia
}

\section{Francisco Javier López-Ferrández}

DOI: $10.5294 /$ pacla.2020.23.2.8

Para citar esta reseña / To cite this review / Para citar esta resenha López-Ferrández, F. J. (2020). Comunicación para el cambio social: interconectando experiencias y aprendizajes de dentro y fuera de la academia. Palabra Clave, 23(2), e2328. https://doi.org/10.5294/pacla.2020.23.2.8

Reseña de libro: Amador Iranzo y Alessandra Farné (Coords.) (2019). Comunicación para el cambio social: propuestas para la acción. Valencia, España: Tirant Lo Blanch. ISBN: 978-8417706-11-1, 260 páginas.

En una entrevista realizada por el semanario chileno The Clinic, Bruno Latour aseguraba: "El capitalismo nunca será subvertido, no está hecho para eso. El capitalismo será aspirado hacia abajo, por así decirlo, por las alternativas que aparecerán en todas partes del mundo. Porque tal vez no hay planeta suficiente para el capitalismo" (Milos y Wolff, 2015). En esta línea, se posicionaba también Tomás Villasante cuando aseguraba que más que subvertir ideológicamente era necesario "revertir" las estructuras “'desde dentro, y/o 'en paralelo' o 'desde fuera', pero siempre desbordando 'desde abajo', [lo que] significa estar más unidos por una metodología del hacer que por alguna ideología" (2012, p. 271). En estos tiempos de emergencia climática y de "guerra contra la vida" (Herrero, 2013, p. 279), detectar esos desbordes y contribuir a ellos se convierte, como apuntan

1 https://orcid.org/0000-0003-2529-8723. Universitat Jaume I, España. ferrandf@uji.es 
Iranzo y Farné (2019, p. 19), "no solo en una obligación ética, sino casi en un requisito para la supervivencia”.

Comunicación para el cambio social: propuestas para la acción contribuye, precisamente, a ello. A localizar, analizar y poner en diálogo diferentes experiencias y corrientes sociales que, "no solo reconocen que el mundo debe cambiar de manera urgente, sino que, de hecho, lo están cambiando" (Polo y Santolino, 2019, p. 16). Y lo hace recogiendo y aplicando todo el bagaje que los estudios sobre comunicación para el cambio social han ido acumulando en las últimas décadas. Aprendizajes interdisciplinares que vienen de corrientes de pensamiento e investigación como las pedagogías críticas, los estudios de paz, los estudios culturales, los estudios de género o los estudios poscoloniales, así como de la experiencia de aquellos colectivos y comunidades que han tratado de darse una narrativa común y reclamar su "poder de nombrar" (Melucci, 1996) y de participar de modo activo en la esfera pública. Lo hace, por tanto, aportando un diálogo permanente entre academia y sociedad civil organizada (a través de ONG o de colectivos y movimientos sociales) y convirtiendo este volumen en una aproximación que integra las principales reflexiones teóricas sobre comunicación transformadora y el análisis empírico de experiencias aplicadas en diferentes latitudes (Latinoamérica, África, Europa y Turquía).

De este modo, el libro coordinado por Iranzo y Farné recoge, especialmente en sus capítulos II y III (firmados por Eloísa Nos-Aldás y Thomas Tufte, respectivamente), algunos de los principales planteamientos teóricos abiertos en los estudios de comunicación para el cambio social en los últimos años. Aporta herramientas conceptuales para abordar las interdependencias entre prácticas comunicativas y procesos sociales, potenciar vías para generar participación, implicación y compromiso político en sectores amplios de población, y para evaluar — con perspectivas a largo plazo - cómo los contextos de apertura de oportunidad de mediación (Cammaerts, 2012) pueden impulsar procesos de transformación de injusticias y desigualdades por vías pacíficas mediante estrategias comunicativas culturalmente eficaces (Nos-Aldás, 2007). 
Además, resulta especialmente estimulante el espacio que la obra dedica a reflexionar sobre el "testimonio ético" (Oliver, 2004) como herramienta de cambio social. Estas aportaciones teóricas plantean la necesidad de superar categorías como la de "reconocimiento" o "reparación", ya que perpetúan una relación asimétrica y de dependencia entre los grupos dominantes (que reconocen) y agraviados (que son reconocidos). Frente a estas nociones, se presenta la necesidad de prestar atención al testimonio (centrado tanto en los hechos objetivos - lo vivido- como en lo experimentado desde la subjetividad — lo sentido-), a fin de generar representaciones que potencien la comprensión y, sobre todo, la responsabilidad de las audiencias, así como su implicación en la transformación de injusticias.

Junto con las aportaciones teóricas, el libro cuenta con una serie de análisis empíricos que abordan diferentes estrategias comunicativas de cambio social que se están implementando en el escenario actual de hibridismo mediático (Chadwick, 2013). Los resultados de los análisis ponen en valor tanto las potencialidades de los contextos comunicativos actuales como los retos que enfrentan las iniciativas analizadas. En este sentido, además de la amplitud geográfica, el volumen destaca por ofrecer estudios de caso que entrelazan diferentes perspectivas y estrategias. Desde una óptica cercana a los estudios de género, encontramos trabajos sobre la representación de los colectivos LGTBIQ en series de ficción y sobre las campañas digitales para denunciar el denominado síndrome de la lesbiana muerta (SLM). También encontramos un análisis de las herramientas para testimoniar la violencia contra las mujeres en la República Democrática del Congo y un capítulo dedicado al análisis de la representación de la mujer en el discurso y la comunicación científica en el contexto occidental. Por otra parte, desde una óptica cercana al ecofeminismo y a los estudios de paz, hallamos trabajos sobre proyectos comunicativos que están utilizando el testimonio ético para denunciar el neocolonialismo, el extractivismo y la violencia política en América Latina, especialmente en Colombia y en Honduras. Y, por último, se ofrecen análisis sobre la comunicación de las organizaciones del tercer sector en el contexto español y portugués. 
La diversidad en los estudios de caso, lejos de restar cohesión y solidez al libro, hace que sea posible poner en diálogo estas experiencias y extraer de ellas conclusiones compartidas. Por una parte, esta perspectiva amplia nos permite observar la importancia de la comunicación en los procesos de cambio social y, especialmente, la necesidad de contar con la participación de los actores sociales implicados a la hora de representar y ofrecer narrativas sobre ellos. De lo contrario, se corre el riesgo de incurrir en relatos que apuntalen las desigualdades y que, en determinados casos, incluso pueden generar procesos de revictimización e "interpasividad" (Pfaller, 2017), con los que asistimos desde la distancia, sin implicación y sin participación a discursos de denuncia.

Al mismo tiempo, nos muestra cómo el proceso de hibridación mediática ha abierto ventanas de oportunidad de mediación, pero nos ayuda a poner en valor herramientas tradicionales, como las radios comunitarias, que siguen siendo fundamentales en determinados contextos locales. Los estudios de caso muestran los rituales propios de cada soporte y las potencialidades y los límites que cada uno presenta. En los sistemas político-mediáticos actuales, en los que las luchas locales se integran a menudo con otras a escala global, podríamos decir que el carácter transmedia de las prácticas comunicativas de cambio social aumentan la eficiencia y la eficacia cultural. Estas estrategias "multicapa” (Toret, 2013) pueden ayudar a diseñar contenidos y narrativas adaptadas tanto a las particularidades de las comunidades directamente implicadas como a públicos más amplios.

En definitiva, el volumen coordinado por Iranzo y Farné ofrece una aproximación amplia y rigurosa a proyectos comunicativos que buscan la transformación cultural y política en diferentes latitudes. Este trabajo sirve como herramienta para interconectar experiencias, aprendizajes y reflexiones sobre comunicación para el cambio social pacífico a fin de que estas puedan ser reprogramadas y remezcladas en atención a las particularidades de los contextos locales. En un escenario de crisis orgánica de las democracias liberales (Garcés, 2017), donde el neoconservadurismo ha apuntalado un discurso "retrotópico" (Bauman, 2017) y excluyente, este trabajo es una 
valiosa contribución para reivindicar el papel activo de la sociedad civil en la construcción de culturas políticas participativas y plurales que aborden simultáneamente problemas locales y globales.

\section{Referencias}

Bauman, Z. (2017). Retrotopía. Barcelona, España: Paidós.

Cammaerts, B. (2012). Protest logics and the mediation opportunity structure. European Journal of Communication, 27(2), 117-134. https:// doi.org/10.1177/0267323112441007

Chadwick, A. (2013). The hybrid media system: Politics and power. Oxford, RU: Oxford University Press.

Garcés, M. (2017). Nueva ilustración radical. Barcelona, España: Anagrama.

Herrero, Y. (2013). Miradas ecofeministas para transitar a un mundo justo y sostenible. Revista de Economía Crítica, 16(2), 278-307. Recuperado de http:/ /www.revistaeconomiacritica.org/sites/default/files/revistas/n16/09_YayoHerrero.pdf

Iranzo, A. y Farné, A. (2019). Comunicación para el cambio social: hacia narrativas transformadoras. En A. Iranzo y A. Farné (Coords.), Comunicación para el cambio social: propuestas para la acción. (pp. 1924). Valencia, España: Tirant Lo Blanch.

Melucci, A. (1996). Challenging codes: Collective action in the information age. Cambridge, RU: Cambridge University Press.

Milos, D. y Wolff, M. (2015, febrero 4). Bruno Latour, sociólogo y antropólogo francés: "El capitalismo nunca será subvertido, será aspirado hacia abajo". Recuperado de https://www.theclinic.cl/2015/02/04/ bruno-latour-sociologo-y-antropologo-frances-el-capitalismonunca-sera-subvertido-sera-aspirado-hacia-abajo/ 
Nos-Aldás, E. (2007). Lenguaje publicitario y discursos solidarios: eficacia publicitaria, ¿eficacia cultural? Barcelona, España: Icaria.

Oliver, K. (2004). Witnessing and testimony. Parallax, 10(1), 78-87. https://doi.org/10.1080/1353464032000171118

Pfaller, R. (2017). Interpassivity: The aesthetics of delegated enjoyment. Edimburgo, Escocia: Edinburgh University Press.

Polo, Y.y Santolino, M. (2019). Prólogo. En A. Iranzo y A. Farné (Coords.), Comunicación para el cambio social: propuestas para la acción. (pp. 13-17). Valencia, España: Tirant Lo Blanch.

Toret, J. (Coord.) (2013). Tecnopolítica: la potencia de las multitudes conectadas. El sistema red $15 \mathrm{M}$, un nuevo paradigma de la política distribuida. IN3 Working Paper Series. Recuperado de http://in3wps.uoc.edu/in3/ca/index.php/in3-working-paper-series/article/view/1878/0.html

Villasante, T. (2012). Nuevas metodologías participativas en acción. En T. R. Villasante, M. Canales, K. Duarte y A. Opazo (Eds.), Construyendo democracias y metodologías participativas desde el Sur. (pp. 261-278). Santiago de Chile, Chile: LOM. 